\title{
Prevalensi Bahaya Potensial Kesehatan dan Keselamatan Kerja pada Pengrajin Emping dan Keripik di Kota Cilegon Banten
}

\author{
Yosephin Sri Sutanti ${ }^{1}$,Yusuf Handoko ${ }^{2}$ \\ ${ }^{1,2)}$ Universitas Kristen Krida Wacana, Fakultas Kedokteran, Departemen K3, \\ Jl. Arjuna Utara 6 Jakarta \\ Email:yosephin.sri@ukrida.ac.id, yusufhandoko@ukrida.ac.id
}

\begin{abstract}
ABSTRAK
Kesehatan dan Keselamatan Kerja (K3) pada sektor informal di Indonesia belum banyak diteliti, padahal sebagian besar pekerja di Indonesia adalah pekerja di sektor informal yang banyak terpajan bahaya potensial selama bekerja. Penelitian pada sektor informal ini mengambil populasi pengrajin emping dan keripik di Kota Cilegon, karena kota ini merupakan kota percontohan untuk K3 Sektor Informal Indonesia. Adapun tujuan penelitian ini adalah mendapatkan data prevalensi pajanan bahaya potensial pada pengrajin emping dan keripik di Kota Cilegon. Sampel penelitian sebagai subyek penelitian ditentukan secara purposive, berdasarkan penetapan Pos UKK (Usaha Kesehatan Kerja) Emping dan Keripik binaan Dinas Kesehatan Kota Cilegon, sebanyak 64 orang. Metode yang digunakan adalah observasi, wawancara dan kuesioner serta pengukuran terhadap lingkungan kerja. Pengumpulan data pajanan fisik menggunakan soundlevel meter, luxmeter dan alat pengukur suhu serta pajanan ergonomik menggunakan Nordic bodymap discomfort, sedangkan pajanan psikologis menggunakan kuesiner stress kerja. Hasil penelitian menunjukkan bahwa seluruh pengrajin (100\%) mengalami masalah muskuloskeletal berupa nyeri mulai dari skala agak nyeri sampai nyeri sekali. Pengukuran pajanan fisik suhu dan penerangan sudah di luar ambang batas normal tetapi relatif belum menimbulkan gangguan pada pengrajin (suhu berkisar 26-31 derajat Celcius, penerangan 100-200 lux); adapun kebisingan masih di bawah ambang batas normal (kebisingan rata-rata $61 \mathrm{~dB}$ ). Pajanan psikososial berupa stres kerja didapatkan 74,6\% mengalami cukup stres dan agak stres $25,4 \%$, sedangkan yang mengalami stres tinggi tidak ada.Hal ini menarik mengingat tidak ada yang mengalami stres yang tinggi padahal beban pekerjaan mereka relatif tinggi, dengan penghasilan yang relatif di bawah ratarata.
\end{abstract}

Kata kunci : bahaya potensial, informal, pengrajin emping dan keripik

\section{Pendahuluan}

Upaya kesehatan kerja diselengarakan untuk mewujudkan produktivitas yang optimal dan wajib diselenggarakan di setiap tempat kerja. Adapun keselamatan kerja atau occupational safety secara filosofi diartikan sebagai suatu pemikiran dan upaya untuk menjamin keutuhan dan kesempurnaan baik jasmaniah maupun rohaniah tenaga kerja pada khususnya dan manusia pada umumnya serta hasil budaya dan karyanya. ${ }^{7}$ Menurut ILO setiap tahun ada lebih dari 250 juta kecelakaan di tempat kerja dan lebih dari 160 juta pekerja menjadi sakit karena bahaya di tempat kerja. ${ }^{2}$ Angka menunjukkan, biaya manusia dan sosial dari 
produksi terlalu tinggi. Di lain pihak, angka Penyakit Akibat Kerja (PAK) sampai saat ini belum jelas,apalagi yang berasal dari sektor informal. ${ }^{7}$

Salah satu industri sektor informal yang cukup berkembang di kota Cilegon adalah upaya yang dilakukan oleh pengrajin keripik dan emping ${ }^{3}$ Bahaya potensial dilihat dalam berbagai pajanan, antara lain pajanan fisika, ergonomis, dan psikososial, yang terdapat di lingkungan kerja. Pajanan fisika mencakup suhu yang panas, penerangan/cahaya yang kurang, dan kebisingan. Pajanan ergonomis tampak dari buruknya adaptasi terhadap sistem, alat, prosedur kerja (fitting the job and tool to the man), yang dapat dinilai dari Nordic bodymap discomfort dan terakhir, pajanan psikososial terkait dengan stres kerja. ${ }^{1,7}$

Kesehatan dan keselamatan kerja (K3) merupakan instrumen yang memproteksi pekerja, perusahaan, lingkungan hidup, dan masyarakat sekitar dari bahaya akibat kecelakaan kerja. ${ }^{7}$ Lebih jauh, Suma'mur mengemukakan, perlindungan tersebut merupakan hak asasi pekerja yang wajib dipenuhi oleh individu maupun organisasi, yang bertujuan mencegah, mengurangi, bahkan menihilkan risiko kecelakaan kerja (zero accident). K3 menjadi semakin penting karena berdampak pada produktivitas, kualitas kehidupan kerja, dan kinerja..

\section{Metode Penelitian}

Pendekatan yang digunakan dalam penelitian ini adalah perpaduan metode kuantitatif dan kualitatif (combine method). Dengan pendekatan ini memungkinkan dilakukannya kajian yang mendalam dan dapat digeneralisasikan pada populasi yang lebih luas. Populasinya adalah seluruh pengrajin emping dan keripik di Kota Cilegon. Berdasarkan data dari Dinas Kesehatan Kota Cilegon, ada kurang lebih sebanyak 20 kelompok pengrajin UKK (Usaha Kesehatan Kerja). Adapun sampel penelitian sebagai subyek penelitian ditentukan secara purposive, berdasarkan penetapan masing-masing dua Pos UKK Emping dan Keripik binaan Dinas Kesehatan Kota Cilegon.

\section{Teknik Pengumpulan dan Analisis Data}

Metode yang digunakan dalam pengumpulan data adalah observasi, wawancara dan kuesioner serta pengukuran terhadap lingkungan kerja. Pengumpulan data pajanan fisik menggunakan soundlevel meter, luxmeter dan alat pengukur suhu serta pajanan ergonomik menggunakan Nordic bodymap discomfort, sedangkan pajanan psikologis menggunakan kuesioner stres kerja (dikonstruksi oleh Manurung, 2017 berdasarkan konsep Igor, 1997). Adapun analisis data secara manual, dengan menggunakan penghitungan prevalensi secara kuantitatif, berdasarkan hasil pengukuran atau skoring yang didapat dari lapangan.

\section{Hasil dan Pembahasan}

Sebagian besar pengrajin adalah perempuan, dengan rata-rata usia 45,5 tahun dan sebesar $89,3 \%$ sudah bekerja lebih dari 5 tahun. Pendidikan pengrajin sebagian besar $(82,5 \%)$ adalah setingkat SLTP, SD, bahkan tak sekolah. Adapun pekerjaan pengrajin sebagian besar merupakan pekerjaan utama $(79,4 \%)$, bukan merupakan sampingan.

Hasil observasi dari pengrajin emping sebagai berikut : emping dibuat dari bahan baku murni biji emping melinjo tua, tanpa campuran, yang diolah dengan cara dipipihkan kemudian dikeringkan/dijemur dengan memanfaatkan energi alam sinar matahari. Hasil produksi yang dikerjakan dengan tuntutan kerajinan, ketekunan dan kesabaran tersebut, mempunyai kualitas dan kuantitas yang cukup baik, terutama di luar musim hujan dan pasar yang cukup baik terutama menjelang hari - hari besar.

Adapun proses produksi emping sebagai berikut: kulit melinjo dikupas lalu dipanaskan pada pasir di atas api (disangrai) dan diangkat. Melinjo lalu dipecahkan kulitnya lalu diletakkan di atas meja kemudian dipukul-pukul dengan palu sampai pipih, kemudian dijemur.

Sementara, produksi kripik menggunakan bahan dasar, seperti singkong, sukun, pisang, ataupun emping. Bahan tambahannya minyak goreng dan bumbu-bumbu sesuai dengan kebutuhan konsumen. Alur proses produksi keripik adalah sebagai berikut : bahan dasar dikupas lalu diiris tipis-tipis dan direndam/dicuci dalam baskomb berisi air. Sementara itu disiapkan minyak untuk proses penggorengan. Bahan-bahan tersebut dimasukkan dalam minyak goreng yang panas dan ditiriskan, lalu ditunggu dingin. Jika sudah dingin, mulai proses pengemasan dan pelabelan produk. Hal tersebut dilakukan, kecuali pada emping yang biasanya langsung digoreng.

\section{Bahaya Potensial Pajanan Fisika}

Suhu yang dialami oleh para pekerja pada saat melakukan penggorengan keripik adalah suhu panas yang diterima tubuh dari udara ruang kerja dan panas tubuh yang sulit dilepas ke udara ruang kerja, yang dapat merupakan beban kerja bagi pekerja. Akibatnya suhu badan pekerja akan meningkat, sehingga kapasitas, efektivitas, 
dan efisiensi kerja menjadi menurun. Suhu yang dianjurkan di tempat kerja yaitu sekitar 24-26 derajat Celcius. ${ }^{1}$ Lebih jauh, dikatakan bahwa suhu yang terlalu panas dapat menimbulkan efek fisiologis pada tubuh, seperti meningkatnya kelelahan, efisiensi kerja fisik dan mental menurun, denyut jantung dan tekanan darah meningkat, aktivitas organ-organ pencernaan menurun, suhu tubuh meningkat, dan produksi keringat bertambah yang bisa mengakibatkan dehidrasi. Pada pengukuran di lokasi, ditemukan suhu berkisar antara 26-31 derajat Celcius, namun karena sebagian besar pekerjaan dilakukan di ruang terbuka, maka terjadilah sirkulasi udara yang relatif baik. Tampaknya pajanan suhu ini tidak menjadi masalah bagi para pengrajin.

Penerangan/cahaya yang relatif kurang didapatkan pada tempat penggorengan keripik. Di dalam ruangan tidak terdapat cahaya buatan seperti lampu bohlam, hanya mengandalkan cahaya alami yang berasal dari ventilasi buatan yang minim. Bila penerangan di tempat kerja kurang dari standar yang seharusnya dapat berakibat kelelahan lebih cepat pada penglihatan karena membutuhkan tenaga ekstra untuk melihat pekerjaannya agar tidak terjadi kesalahan dan kecelakaan kerja. ${ }^{7}$ Sementara, Hunter menekankan bila terjadi penerangan yang melebihi dari standar yang ditentukan, maka mata akan menambah upaya untuk mengurangi cahaya yang masuk ke dalam mata agar tidak silau, sehingga menjadi beban tambahan aktivitas mata dan mata lebih cepat mengalami kelelahan. ${ }^{1}$

Hasil observasi menunjukkan bahwa ruangan untuk pengrajin keripik seluas kira-kira $12 \mathrm{~m}$ persegi, hanya mengandalkan cahaya dari sinar matahari saja, kira-kira 100-200 lux.

Padahal seharusnya penerangan yang dibutuhkan perhitungannya adalah sebagai berikut: 1 lux $=0,001496$ watts $/ \mathrm{m}$ persegi, sehingga untuk pekerjaan rutin sebesar $300 \mathrm{lux}=0,4488$ watts $/ \mathrm{m}$ persegi. Dengan demikian maka untuk ruangan seluas $12 \mathrm{~m}$ persegi maka dibutuhkan $12 \times 0.4488=5,36$ watts (kira-kira dibulatkan menjadi 6 watts). Pencahayaan adalah jumlah penyinaran pada suatu bidang kerja yang diperlukan untuk melaksanakan kegiatan secara efektif. ${ }^{4}$ Pencahayaan minimal yang dibutuhkan menurut jenis kegiatanya dapat dilihat pada tabel 1.

Tabel 1. Tingkat pencahayaan lingkungan kerja

\begin{tabular}{|c|c|c|}
\hline Jenis Kegiatan & Lux & Keterangan \\
\hline $\begin{array}{l}\text { Pekerjaan kasar dan tidak } \\
\text { terus - menerus }\end{array}$ & 100 & $\begin{array}{l}\text { Ruang penyimpanan penyimpanan \& ruang peralatan/instalasi } \\
\text { pekerjaan yang kontinyu }\end{array}$ \\
\hline $\begin{array}{l}\text { Pekerjaan kasar dan terus - } \\
\text { menerus }\end{array}$ & 200 & Pekerjaan dengan mesin dan perakitan kasar \\
\hline Pekerjaan rutin & 300 & $\begin{array}{l}\text { Ruang administrasi, ruang kontrol, pekerjaan mesin \& } \\
\text { perakitan/penyusun }\end{array}$ \\
\hline Pekerjaan agak halus & 500 & $\begin{array}{l}\text { Pembuatan gambar atau bekerja dengan mesin kantor, pekerjaan } \\
\text { pemeriksaan atau pekerjaan dengan mesin }\end{array}$ \\
\hline Pekerjaan halus & 1000 & $\begin{array}{l}\text { Pemilihan warna, pemrosesan teksti, pekerjaan mesin halus \& } \\
\text { perakitan halus }\end{array}$ \\
\hline Pekerjaan amat halus & $\begin{array}{c}1500 \\
\text { Tidak } \\
\text { menimbulkan } \\
\text { bayangan }\end{array}$ & $\begin{array}{l}\text { Mengukir dengan tangan, pemeriksaan pekerjaan mesin dan } \\
\text { perakitan yang sangat halus }\end{array}$ \\
\hline Pekerjaan terinci & $\begin{array}{c}3000 \\
\text { Tidak } \\
\text { menimbulkan } \\
\text { bayangan }\end{array}$ & Pemeriksaan pekerjaan, perakitan sangat halus \\
\hline
\end{tabular}

KEPMENKES RI. No. 1405/MENKES/SK/XI/02

Pajanan fisika yang berikut adalah kebisingan yang dapat terjadi di area penggorengan yang terus menerus ataupun area penumbukan yang intermiten (terputus-putus). Kelebihan yang melebihi ambang 
batas, selain dapat menimbulkan ganguan pada telinga, juga dapat menimbulkan kelelahan pada pekerja. ${ }^{7}$ Sebagian pengrajin melalui kuesiner menyatakan sudah mulai terganggu pendengarannya. Namun demikian, hasil pengukuran di area menunjukkan tingkat kebisingan rata-rata sebesar $61 \mathrm{~dB}$. Hal ini masih di bawah ambang yaitu $85 \mathrm{~dB}$, namun perlu penelitian fisik dan penunjang selanjutnya untuk memastikan adanya ketulian saraf yang terjadi secara kronis akibat pajanan yang terus menerus.

\section{Bahaya Potensial Pajanan Ergonomi}

Ergonomi adalah ilmu yang mempelajari perilaku manusia dalam kaitannya dengan pekerjaan. ${ }^{6}$ Sasaran ilmu ergonomi berkaitan dengan kondisi kerja, cara kerja, posisi kerja, peralatan, tempat kerja, dan lingkungan kerja. Ergonomi berfungsi untuk penyesuaian peralatan dan tempat kerja dengan dimensi tubuh manusia, agar manusia sebagai pelaksana tidak mengalami kelelahan, dapat mengatur suhu ruang kerja, pencahayaan, dan kondisi lingkungan kerja yang baik. ${ }^{10}$ Dari aktivitas kerja para pengrajin emping dan keripik didapatkan posisi pekerja saat bekerja tidak ergonomis, dimana pekerja harus membungkuk terus saat bekerja, selama minimal 4 jam tanpa istirahat atau relaksasi, kecuali ke kamar kecil. Hasil penelitian menunjukkan bahwa seluruh pengrajin (100\%) mengalami masalah muskuloskeletal berupa nyeri mulai dari skala agak nyeri sampai nyeri sekali. Hasil kuesioner pada tabel 2 juga memperlihatkan bahwa sebagian besar pengrajin mengeluh adanya gangguan muskuloskeletal, mulai dari skala agak sakit sampai sakit sekali (skala 2-4), khususnya pada bagian punggung, bahu kanan dan pergelangan tangan kanan yang angka kesakitannya masing-masing mencapai di atas $50 \%$.

\section{Bahaya Potensial Pajanan Psikososial}

Pajanan psikologis yang paling sering dialami oleh pekerja adalah stres, kelelahan kerja, dan burnout. Selye menyebutkan stres sebagai sebuah reaksi psikologis untuk menyatakan ancaman dari situasi lingkungan. Stres dapat juga dipahami sebagai suatu keadaan ketegangan fisik /mental atau kondisi yang menyebabkan ketegangan saat seseorang menjalani kehidupannya sehari-hari ; yang dengan bersamaan mengatur pikiran dan tubuh dengan tugas yang dimilikinya. ${ }^{5}$ Hasil kuesioner menunjukkan adanya sebagian pengrajin yang menyatakan adanya masalah psikologis berupa stress yang tampaknya berhubungan dengan pekerjaannya. Sebanyak 74,6 \% mengalami stress cukup tinggi dan sisanya stress yang agak tinggi. Tidak ada yang mengalami stress yang tinggi. Hal ini menarik mengingat tidak ada yang mengalami stres yang tinggi padahal beban pekerjaan mereka relatif tinggi, dengan penghasilan yang relatif di bawah rata-rata. Pajanan psikologis yang terus menerus dapat berakibat pada menurunnya produktivitas dan kualitas kerja.

\section{Kesimpulan dan Saran}

Dalam proses produksi emping dan keripik ditemukan bahaya potensial, yang dapat menimbulkan penyakit dan mengganggu kesehatan dan keselamatan kerja. keripik. Pajanan bahaya potensial yang dominan berupa gangguan ergonomik, yang dialami oleh semua pengrajin, pada tempat/lokasi tubuh yang berbeda. Pajanan psikososial berupa stres kerja, lalu diikuti masalah pajanan fisik yang berupa pajanan penerangan dan suhu yang perlu dikaji ulang dan dilakukan penelitian lanjutan yang lebih luas dan mendalam.

Tabel 2. Jenis Keluhan dan Tingkat Keluhan

\begin{tabular}{|c|c|c|c|c|c|c|c|c|c|}
\hline \multicolumn{2}{|c|}{ Jenis Keluhan } & \multirow{2}{*}{$\begin{array}{c}\begin{array}{c}\text { Tingkat } 1 \\
\text { (tak sakit, \%) }\end{array} \\
37\end{array}$} & \multicolumn{3}{|c|}{$\begin{array}{c}\text { Tingkat } 2 \\
\text { (agak sakit, \%) }\end{array}$} & \multicolumn{2}{|c|}{$\begin{array}{l}\text { Tingkat } 3 \\
\text { (sakit, \%) }\end{array}$} & \multicolumn{2}{|c|}{$\begin{array}{c}\text { Tingkat } 4 \\
\text { (sangat sakit \%) }\end{array}$} \\
\hline 0 & Leher atas & & 58,7 & 14 & 22,2 & 10 & 15,9 & 2 & 3,2 \\
\hline 1 & Leher bawah & 50 & 79,4 & 9 & 14,3 & 4 & 6,3 & 0 & 0 \\
\hline 2 & Bahu Kiri & 55 & 87,3 & 8 & 12,7 & 0 & 0 & 0 & 0 \\
\hline
\end{tabular}




\begin{tabular}{|c|c|c|c|c|c|c|c|c|c|}
\hline 3 & Bahu Kanan & 26 & 41,3 & 16 & 25,4 & 20 & 31,7 & 1 & 1,6 \\
\hline 4 & Lengan atas kiri & 55 & 87,3 & 4 & 6,4 & 3 & 4,8 & 1 & 1,6 \\
\hline \multirow[t]{2}{*}{5} & Punggung & 31 & 49,2 & 17 & 27,0 & 15 & 23,8 & 0 & 0 \\
\hline & Lengan atas & & & & & & & & \\
\hline 6 & kanan & 35 & 55,6 & 11 & 17,5 & 17 & 27,0 & 0 & 0 \\
\hline 7 & Pinggang & 32 & 50,8 & 17 & 27,0 & 14 & 22,2 & 0 & 0 \\
\hline 8 & Bokong & 43 & 68,3 & 10 & 15,9 & 9 & 14,3 & 1 & 1,6 \\
\hline 9 & Pantat & 47 & 74,6 & 9 & 14,3 & 7 & 11,1 & 0 & 0 \\
\hline 10 & Siku kiri & 54 & 85,7 & 5 & 7,9 & 4 & 6,3 & 0 & 0 \\
\hline \multirow[t]{2}{*}{11} & Siku kanan & 38 & 60,3 & 13 & 20,6 & 12 & 19,0 & 0 & 0 \\
\hline & Lengan bawah & & & & & & & & \\
\hline \multirow[t]{2}{*}{12} & kiri & 54 & 85,7 & 6 & 9,5 & 3 & 4,8 & 0 & 0 \\
\hline & Lengan & & & & & & & & \\
\hline \multirow[t]{2}{*}{13} & bawahkanan & 38 & 60,3 & 12 & 19,0 & 12 & 19,0 & 1 & 1,6 \\
\hline & Pergelangan t. & & & & & & & & \\
\hline \multirow[t]{2}{*}{14} & kiri & 51 & 81,0 & 6 & 9,5 & 5 & 7,9 & 1 & 1,6 \\
\hline & Pergelangan $t$ & & & & & & & & \\
\hline 15 & kanan & 29 & 46,0 & 18 & 28,6 & 15 & 23,8 & 1 & 1,6 \\
\hline 16 & Tangan kiri & 54 & 85,7 & 4 & 6,3 & 5 & 7,9 & 0 & 0 \\
\hline 17 & Tangan kanan & 33 & 52,4 & 18 & 28,6 & 12 & 19,0 & 0 & 0 \\
\hline 18 & Paha kiri & 48 & 76,2 & 7 & 11,1 & 7 & 11,1 & 1 & 1,6 \\
\hline 19 & Paha kanan & 49 & 77,8 & 9 & 14,3 & 4 & 6,3 & 1 & 1,6 \\
\hline 20 & Lutut kiri & 39 & 62,0 & 14 & 22,2 & 8 & 12,7 & 2 & 3,2 \\
\hline 21 & Lutut kanan & 39 & 62,0 & 15 & 23,8 & 7 & 11,1 & 2 & 3,2 \\
\hline 22 & Betis kiri & 49 & 77,8 & 9 & 14,3 & 4 & 6,3 & 1 & 1,6 \\
\hline 23 & Betis kanan & 48 & 76,2 & 11 & 17,5 & 3 & 4,8 & 1 & 1,6 \\
\hline \multirow[t]{2}{*}{24} & Pergel. kaki kiri & 43 & 68,3 & 14 & 22,2 & 5 & 7,9 & 1 & 1,6 \\
\hline & Pergel.kaki & & & & & & & & \\
\hline 25 & kanan & 53 & 84,1 & 7 & 11,1 & 2 & 3,2 & 1 & 1,6 \\
\hline
\end{tabular}


[1] Hunter, D, Disease of Occupation.London. (2010).

[2] ILO, Pedoman pelatihan untuk manajer dan pekerja. Keberlanjutan melalui perusahaan yang kompetitif dan bertanggung jawab (SCORE). Keselamatan dan Kesehatan Kerja Modul 5. (2010) .

[3] Kesepakatan Bersama Dirjen Bina Kesehatan Masyarakat Kementerian Kesehatan RI dengan Pemerintah Kota Cilegon No.HK.06.01/B6/1261/2010 dan No.490/25-HUK/2010. Pembentukan Cilegon sebagai Kota Percontohan Bidang Kesehatan Kerja.(2010).

[4] Keputusan Mentri Kesehatan RI. No. 1405/MENKES/SK/XI/2002.(2002).

[5] Munandar, A.S, Psikologi Industri dan Organisasi. (2001).

[6] Pheasant, S., Ergonomics, Work, and Health. (2011).

[7] Suma'mur P. K., Higiene Perusahaan dan Kesehatan Kerja. (2014).

[8] Sutanti, Y.S., Identifikasi Bahaya Potensial pada Pengrajin Emping dan Keripik. (2015).

[9] Tim Mahasiswa Fakultas Kedokteran UKRIDA. Plant Survey Pos Upaya Kesehatan Kerja (UKK) pada Pengrajin Emping dan Kripik.Kota Cilegon. (2015).

[10] WHO., Introduction to Ergonomics.Geneva. (2010). 